\title{
Detection of Some Biogenic Amines content in Thai Sauces
}

\author{
Pornpimol Muangthai ${ }^{1}$, Prangthip Nakthong ${ }^{1}$ \\ ${ }^{1}$ Department of Chemistry, Faculty of Science, Srinakharinwirot University,Bangkok, Thailand
}

\begin{abstract}
There are many toxic substances present in food, biogenic amine compounds are the one in those toxic substances. An important biogenic amines found in food are histamine, putrescine,cadaverine and phenylethylamine. The aim of this work was to screening test the histamine, cadaverine and putrescine in seasoning sauces made from fish, soybean, oyster and mushroom that sold in Thailand by TLC method.Then, the present biogenic amine was analysed its content by Spectrofluorometry technique. The result from TLC screening test showed only histamine in 32 sample sauce products. Soy sauce products contained highest histamine content approximately $17.76-25.33 \mathrm{mg} / \mathrm{kg}$, the mushroom vegetarian sauce contained the lowest histamine approximately $8.02-8.15 \mathrm{mg} / \mathrm{kg}$. The result from monitoring toxic substances as biogenic amine found only histamine in all sauces that sold in Thailand, which its content not exceed the recommendation values.
\end{abstract}

Keywords: Biogenic amines, histamine, putrecine, cadaverine, Thai sauces

\section{Introduction}

Biogenic amines (BAs) are nitrogenous low molecular weight organic compounds, which have been derived from enzymatic decarboxylation of some free amino acids and proteins [1-3] as in the equation 1)

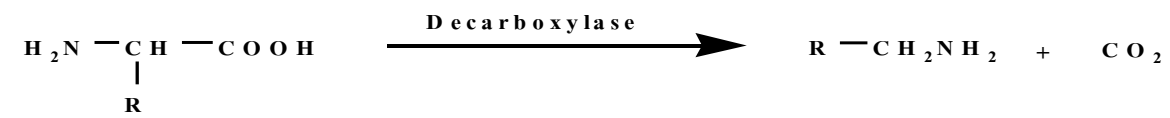

The Biogenic amines can be classified into 3 groups according to their structures such as aromatic amines, aliphatic diamines and heterocyclic amine [4]. These biogenic amines involve in neurotransmitters system such as acetylcholine, catecholamines, and serotonin[5]. The formation of biogenic amines in food relate to the decarboxylation reaction of amino acids by microorganism[6]. The important biogenic amines that found in food are histamine, tyramine, putrescine, cadaverine and phenylethylamine. In this work, histamine, cadaverine and putescine are scoped. Histamine has the IUPAC name as 2-(1H-imidazol-4-yl)ethanamine and its structural formular shows as in Fig.1

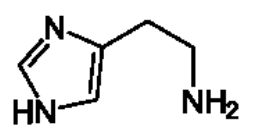

Figure 1. The structural formular of histamine [7]

Histamine are products from the decarboxylation of histidine as showed in equation 2).<smiles>N[C@@H](Cc1c[nH]cn1)C(=O)O</smiles>

histidine<smiles>CC1CC(=O)CC1C(=O)O</smiles>

histamine

It has been implicated as the causative agent in outbreaks of food poisoning where intoxication results from the ingestion of foods containing excessive amounts of histamine[8].

Putrescine is also one of the most common biogenic amine. Its IUPAC name is butane-1,4-diamine as in Fig.2<smiles>NCCCCN</smiles>

Figure 2. The structural formular of putrescine [9]

Putrescine also forms by the decarboxylation of ornitine as equation 3). 


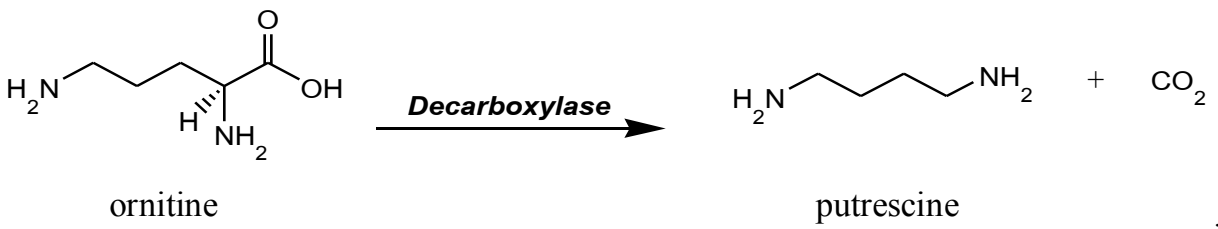

Putrescine is also found in fermented products. Lactic acid bacteria especially lactobacilli and staphylococci able to produce putrescine and cadaverine[10- 13].

Cadaverine is the last one that also be the popular biogenic amine compound, it has an IUPAC name as Pentane-1,5-diamine[14] as in fig.3. It was changed from the decarboxylation of lysine amino acid as in equation 4)

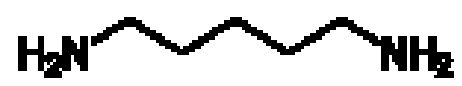

Figure 3. The structural formular of cadaverine[14]

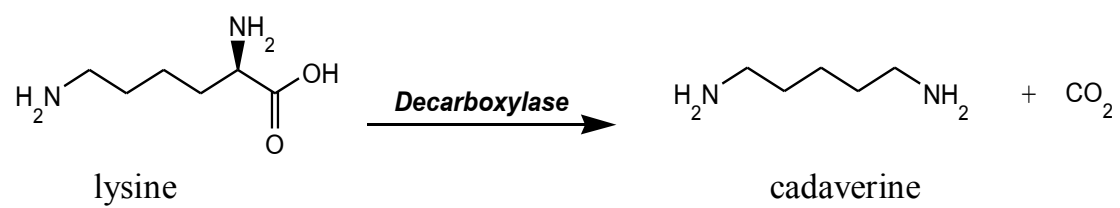

Both putrescine and cadaverine can be formed during the food storage[15-18].The biogenic amines in food effect on the health of the consumers. Some consumer suffered from allergic reactions and showed many symptoms such as difficulty in breathing, itching, rash skin, vomiting, fever and hypertension[5]. There are many food reports referred the high levels of biogenic amines in some food such as fish, fish products and fermented foods[5],[19-21]

Seasoning sauces such as fish sauces, soy sauces and oyster sauces are very important for Thai crusine.There are many works referred about the biogenic amines in fish sauces not only in Thailand but also in other country [22].Especially, histamine was controlled in fish sauce at the level of $40 \mathrm{mg} / 100 \mathrm{~g}$ fish sauce[23]. The other amine such as tyramine was also found in moromi during soy sauce fermentation process[24]. The lastest research work report that tyramine and histamine could be detected in Japanese soy sauce in trace amount level[25].However, there was a few report literature about the above three biogenic amines in other type of seasoning sauces such as oyster sauces, mushroom sauces. The objective of this work was to analyse the histamine ,cadaverine and putrescein in seasoning sauces which made of fish, soybean, oyster and mushroom that sold in Thailand market.The qualitative analysis was preliminary performed to screen biogenic amines by Thin layer Chromatography.Then the content of biogenic amines were analysed by Spectrofluorometric technique.

\subsection{Materials}

\section{Materials And Method}

\subsubsection{Chemicals}

Histamine and putrescine standard were AR grade that purchased from Fluka.Cadaverine standard (AR grade) was purchased from Sigma Aldrich. Methanol(HPLC grade), acetonitrile (HPLC grade) and chloroform (AR grade) were purchased from Merck.Ammonia solution (AR grade), acetic acid (AR grade) and trichloroacetic acid (AR grade) were purchased from Sigma Aldrich. Ninhydrin and KI/I 2 (AR grade) was bought from Merck. $o$-Phthaldialdehyde(OPA)(AR grade) was purchased from Acros. Mercaptoethanol(AR grade) was purchased from Merck.

TLC plate was ready coated silica plate (Silica gel: DC-Fertigfolien ALUGERAM® SIL G/UV254) size $2 \times 8 \mathrm{~cm}$.). Microcapillary tube was VERTICAL ${ }^{\circledR}$ Drummond microcap $5.0 \mu \mathrm{L}, 100 / \mathrm{PK}$.

\subsubsection{Samples}

The sauces samples such as true fish sauces ( 5 samples), mixed fish sauces( 5 samples),soy sauce (5 samples),sweet soy sauces(4 samples), black soy sauces(4 samples),oyster sauces(6 samples) and mushroom vegetarian sauces( 3 samples), all above sample sauces were purchased from Big C supermarket and Lotus supermarket in Bangkok,Thailand. 
2.2 Experimental method

2.2.1 Qualitative Analysis Study

2.2.1.1 Study on the optimization Thin Layer Chromatography systems.

The standard solution of histamine, cadaverine and putrescine were prepared $1 \mathrm{ppm}$ and spotted on ready coated silica plate using microcap capillary. The spotted plate was developed chromatogram in 2 systems as system 1 was methanol : $\mathrm{NH}_{3}: \mathrm{CHCl}_{3}$ and system 2 was methanol : $\mathrm{NH}_{3}$.

The system 1 was prepared as 4 subclass systems by variation of each component solvent for 4 systems as the following

S1.1 methanol : $\mathrm{NH}_{3}: \mathrm{CHCl}_{3}=50: 40: 10 \mathrm{v} / \mathrm{v}$,

S1.2 methanol : $\mathrm{NH}_{3}: \mathrm{CHCl}_{3}=55: 35: 10 \mathrm{v} / \mathrm{v}$

S1.3 methanol : $\mathrm{NH}_{3}: \mathrm{CHCl}_{3}=60: 30: 10 \mathrm{v} / \mathrm{v}$

S1.4 methanol : $\mathrm{NH}_{3}: \mathrm{CHCl}_{3}=60: 35: 5 \mathrm{v} / \mathrm{v}$

The system2(methanol : ammonia ) was also prepared as 8 subclass systems by variation of each component solvent for 8 systems as the following

S2.1 methanol: $\mathrm{NH}_{3}=95: 5 \mathrm{v} / \mathrm{v}$

$\mathrm{S} 2.2$ methanol: $\mathrm{NH}_{3}=90: 10 \mathrm{v} / \mathrm{v}$

$\mathrm{S} 2.3$ methanol: $\mathrm{NH}_{3}=85: 15 \mathrm{v} / \mathrm{v}$,

$\mathrm{S} 2.4$ methanol: $\mathrm{NH}_{3}=80: 20 \mathrm{v} / \mathrm{v}$

$\mathrm{S} 2.5$ methanol: $\mathrm{NH}_{3}=75: 25 \mathrm{v} / \mathrm{v}$,

S2.6 methanol: $\mathrm{NH}_{3}=70: 30 \mathrm{v} / \mathrm{v}$

S2.7 methanol: $\mathrm{NH}_{3}=50: 50 \mathrm{v} / \mathrm{v}$

$\mathrm{S} 2.8$ methanol: $\mathrm{NH}_{3}=5: 95 \mathrm{v} / \mathrm{v}$.

All of the spots on the chromatogram were detected by 2 methods such as incubated in the iodine vapor tank and spraying with ninhydrin reagent.

\subsubsection{Preparation of Analyte Samples}

All seasoning sauce samples such as true fish sauces ,mixed fish sauces ,soy sauces ,sweet soy sauces ,black soy sauces, oyster sauces and mushroom vegetarian sauces were weighed each $3.00 \mathrm{~g}$ and dissolved in $2.5 \mathrm{ml}$ of $10 \%$ TCA and $2.5 \mathrm{ml}$ of $1 \mathrm{M} \mathrm{CH}_{3} \mathrm{COOH}$. The sample solutions were mixed together with vortex mixer and ultrasonic treatment for 5 minutes and filtered through filtered paper (Whatman paper no1.) The sample filtrates were stored at $4{ }^{\circ} \mathrm{C}$, until analysis as in part 2.2.2

\subsubsection{Quantitative Analysis by Spectrofluorometry}

The extracted filtrate sauces samples from2. 2.1.2 were analysed by measurement the fluorescence intensity using method modified from AOAC[26]. The $5 \mu \mathrm{l}$ of $8.0 \times 10^{-5} \mathrm{M}$ standard histamine, cadaverine and puterscine were reacted with $5 \mu \mathrm{l}$ of $8.0 \times 10^{-5} \mathrm{M} o$-phthaldialdehyde in $\mathrm{NaOH}, 1 \mathrm{ml}$ of methanol and $5 \mu \mathrm{l}$ of 2mercaptoethanol.Those reaction tubes were placed in the dark cabin laboratory locker for 3 minutes. The fluorescent intensity of the derivative samples were scanned and measured at emission wavelength of each amine standard by Spectrofluorometer(Jasco FP6200). The biogenic amine contents in all samples were calculated by comparison with standard calibration curves.

\section{Results And Discussion}

The results from part 2.1.1 that studied in the 2 developing solvent systems(system1 and system2) showed that in the system 1 which was prepared 4 subclass systems by variation of each solvent; methanol: $\mathrm{NH}_{3}: \mathrm{CHCl}_{3}$ as 50:40:10v/v,55:35:10 v/v,60:30:10 v/v and 60:35:5 v/v and the system $2(\mathrm{methanol}:$ ammonia ) was also prepared as 8 subclass systems by variation of each solvent ; methanol: $\mathrm{NH}_{3}$ as $95: 5 \mathrm{v} / \mathrm{v}$, $90: 10 \mathrm{v} / \mathrm{v}, 85: 15 \mathrm{v} / \mathrm{v}, 80: 20 \mathrm{v} / \mathrm{v}, 75: 25 \mathrm{v} / \mathrm{v}, 70: 30 \mathrm{v} / \mathrm{v}, 50: 50 \mathrm{v} / \mathrm{v}$ and 5:95 v/v showed that the best system for optimization TLC analysis method was system 2.5 methanol : ammonia with the ratio of 75:25 v/v as in Fig. 4. 


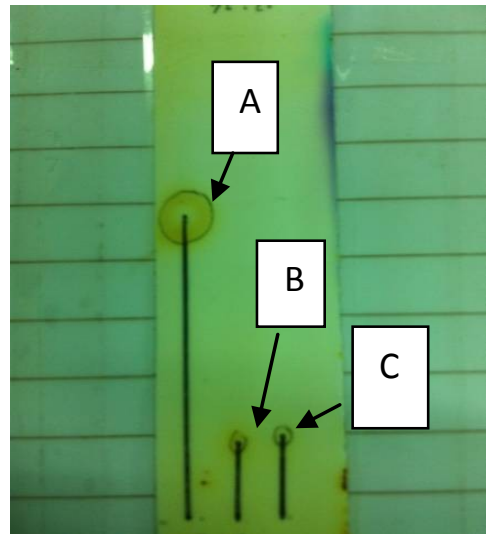

Figure 4. Chromatogram of standard biogenic amines

Note: a represent histamine standard spot ; b represent putrescein standard spot and c represent cadaverine standard spot

The spot on TLC chromatogram could be detected by 2 methods as iodine vapor and $1.5 \%$ ninhydrin in ethanol solution. However, the iodine vapor could easily prepared and lower cost than ninhydrin solution, so this work chose the iodine vapor for spot detection. The optimization method was applied to analyse the three biogenic amines in all those sauces as showed the chromatogram from some sauce sample as in Fig. 5.

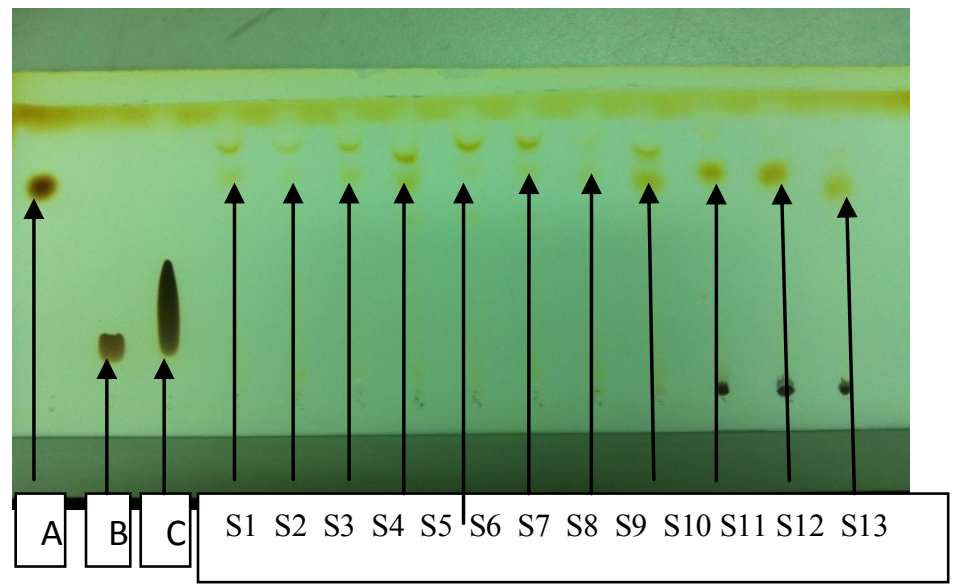

Figure 5 Example Chromatogram of sample compare with standard biogenic amines

Note: a represent histamine standard spot ; b represent putrescein standard spot and c represent cadaverine standard spot, lane S1-13 represent sample spot.

From the qualitative TLC chromatogram showed that all sample sauces contain only histamine as a predominant biogenic amine since the $\mathrm{Rf}$ value of sample nearest 0.7 which relate to $\mathrm{Rf}$ value of histamine standard. This chromatogram could not detected the other 2 biogenic amines of putrescine and cadaverine, since both amine may be detected in storage product as refered by Beneduce et al[27].Bover-Cid et al. [28,] The sample sauce in this experiment was freshly prepared from the factories as the manufacturing date.

After the qualitative screening TLC test on sauce samples, those samples were analysed only histamine content by compare with the standard histamine calibration curve. The result from scanning the histamine standard with Spectrofluorometer showed in Fig.6. 


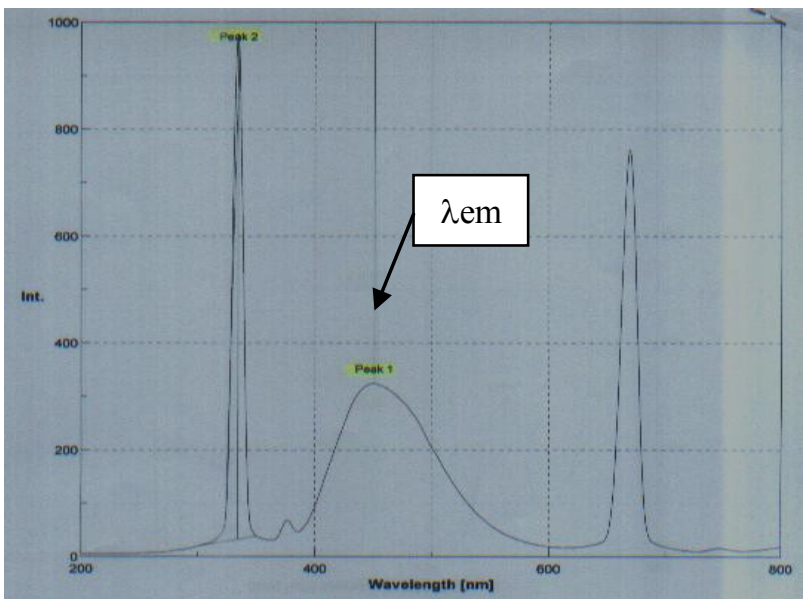

Figure 6. Spectrum of histamine standard solution with emission spectrum at $452 \mathrm{~nm}$

The fluorescence intensities of the histamine standard solutions were recorded and created a standard calibration curve that plotted between the fluorescence intensity $\left(\mathrm{I}_{\mathrm{f}}\right)$ and the concentration of histamine standard.The standard calibration curve showed the linearity range between $1.6 \times 10^{-5}-12.8 \times 10^{-5} \mathrm{M}$ with correlation coefficient of \pm 0.993 . The limit of determination (LOD) and limit of quantitation (LOQ) were $1.30 \mathrm{x}$ $10^{-5}$ and $2.52 \times 10^{-5} \mathrm{M}$, respectively. The relative standard deviation (RSD) was less than $10.0 \%$. So this method showed good results in terms of linearity, accuracy, precision, limits of detection, and limit of quantitation.

The extracted sample from all sauce samples were measured and recorded the fluorescence intensity of emission peak at emission wavelength of $452 \mathrm{~nm}$ and calculated the histamine content in those sauces as in Fig. 7.

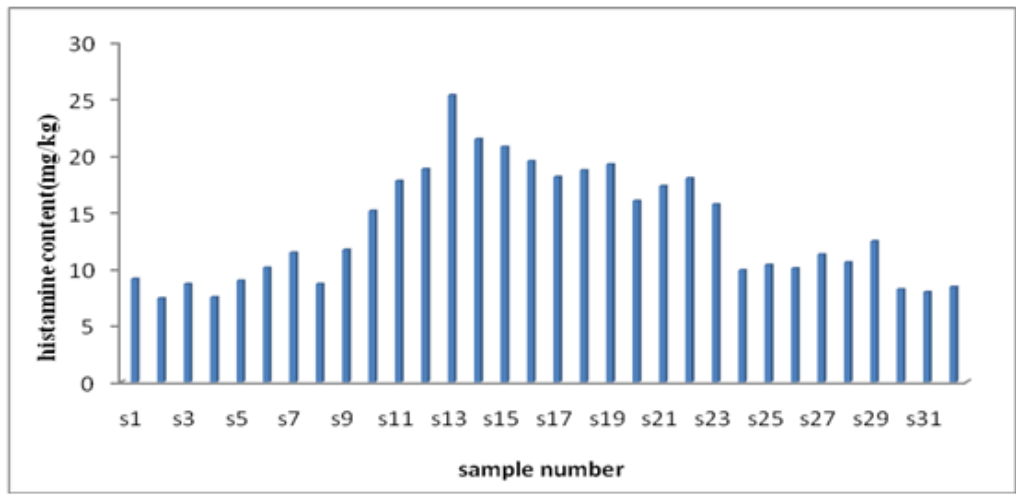

Note:

Figure7. Histamine content $(\mathrm{mg} / \mathrm{kg})$ in Thai sauces samples

s1-s5 represent as mixed fish sauces

s6-s10 represent as pure fish sauces

s11-s15 represent as soy sauces

s16-s19 represent as sweet soy sauces

s20-s24 represent as black soy sauces

s25-s29 represent as oyster sauces

s30-s32 represent as mushroom vegetarian sauces

From those results presented that soy sauces and sweet soy sauces contain highest histamine contents approximately $17.76-25.33 \mathrm{mg} / \mathrm{kg}$, but fish sauce samples group contained histamine approximately $7.50-15.11$ $\mathrm{mg} / \mathrm{kg}$. This may depended on the difference fermentation process and type of microorganisms that effected the histamine content as discussed by Stratton et al.[29-31]. This work supported the report from[25], that refer the histamine content in Japanese soy sauce in trace amount level. The oyster sauces showed histamine content in the same level as in fish sauces samples group. Oyster is also sea food which was referred to contain biogenic amine too[32]. The mushroom vegetarian sauce contained the lowest histamine content approximately 8.02 $8.11 \mathrm{mg} / \mathrm{kg}$. It is very interesting that this sauces which was produced from shitake mushroom contained low histamine content. However, there also had the report about the histamine in mushroom[5].Then histamine was also be detected in low level in mushroom sauces too. 


\section{Conclusion}

This work showed that after the qualitative screening TLC test in this work was the rapid screening method to rapid detect the toxic three types of biogenic amine in Thai sauce products by using the mobile phase system as methanol : ammonia at the ratio $75: 25$ and using iodine vapour for detection spot on chromatogram. The screening time for TLC test not exceed than 10 minute. The result from the screening TLC in all sauces showed that the histamine was the one biogenic amine that be detected in this experiment.After the optimization method of analysis histamine by spectrofluorometry technique, it revealed that Thai sauce products showed the histamine content in the range of $8.02-25.33 \mathrm{mg} / \mathrm{kg}$. This is very low content. The allowed content of histamine in general fish sauce not exceed than $400 \mathrm{mg} / \mathrm{kg}$ [23]. This work also proved that Thai sauces that sold in Thailand contained the low level of biogenic amines as histamine. The consumer that use freshly Thai sauce which sold in Thailand will be safe. However, if that sauces were stored for a long time the content of histamine may increase as referred by M.E.Arena ,et al.[16].

\section{Acknowledgments}

The author wish to thank the Strategic Wisdom and Research Institute of Srinakharinwirot University to support the budget money from Annual government statement of expenditure.

\section{References}

[1]. S K.Sadain and J A.Koropchak .Condensation Nucleation Light Scattering Detection for Biogenic Amines Separated by IonExchange Cromatography. Journal of Chromatography A. 844:1999, 111-118.

[2]. C.Proestos, P.Loukatos and M. Komaitis .Determination of Biogenic Amines in Wines by HPLC with Precolumn Dansylation and Fluorimetric Detection. Food Chemistry. 106:2008, 1218-1224.

[3]. M.H. Silla Santos. Biogenic Amines: Their Importance in Foods. Food Microbiology . 29: 1996,213-231.

[4]. A.Önal. A review: Current analytical methods for the determination of biogenic amines in foods. Food Chemistry. 103:2007, $1475-1486$

[5]. AR .Shalaby, Significance of biogenic amines to food safety and human health,Food Research Int, ,29,1996, 675-690.

[6]. C.Barancin, J.Smoot, R.Findlay and L.Actis, Plasmid-mediated histamine biosynthesis in the bacterial fish pathogen Vibrio anguillarum. Plasmid ,39,1998, 235-244.

[7]. T. B. Paiva,M.Tominaga, A C M. Paiva (1970).Ionization of histamine, N-acetylhistamine, and their iodinated derivatives. Journal of Medicinal Chemistry 13 (4),1970, 689-692.

[8]. S.Bardocz, Polyamines in food and their consequences for food quality and human health. Trends Food Sci. Technol. 6,1995, 341346.

[9]. Lewis, Robert Alan (1998). Lewis' Dictionary of Toxicology. CRC Press.1998,212

[10]. M.K.Kim, J.H.Mah and Hj.Hwang, Biogenic amine formation and bacterial contribution in fish,squid and shellfish. Food Chem. $116,2009,87-95$.

[11]. S.Chytiri , E.Paleologos, I.Savvaidis and M.G.Kontominas, Relation of biogenic amines with microbial and sensory changes of whole and filleted fresh water rainbow trout (Oncorhynchus mykiss) stored on ice. J. Food Prot., 67(5),2004, 960-965.

[12]. E.K.Paleologos, Savvaidis IN and Kontominas MG, Biogenic amines formation and its relation to microbiological and sensory attributes in ice-stored whole, gutted and filleted Mediterranean Sea bass (Dicentrarchus labrax), Food Microbiol, 21,2004, 549557 .

[13]. M.Rezaei, N.Montazeri, HE.Langrudi, B.Mokhayer, M.Parviz and A.Nazarinia, The Biogenic amines and bacterial changes of farmed rainbow trout (Oncorhynchus mykiss) stored in ice. Food Chem.,103,2007, 150-154.

[14]. MT. Saarinen. Determination of Biogenic Amines as Dansyl Derivatives in Intestinal Digesta and Feces by Reversed Phase HPLC. Journal Chromatographia. 55:2002, 297-300.

[15]. EFSA, European Food Safety Authority. Standard sample description for food and feed. , EFSA J,8(1)., 2010, 1-54.

[16]. M.E.Arena, J.M.Landete, MC.Manca de Nadra, I.Pardo and S.Ferrer, Factors affecting the production of putrescine from agmatine by Lactobacillus hilgardii X1B isolated from wine. J.Appl. Microbiol.,105(1),2008,158-165.

[17]. ML.Latorre-Moratalla, S.Bover-Cid and MC.Vidal-Carou, Technological conditions influence aminogenesis during spontaneous sausage fermentation. Meat Sci.,85, $2010,537-541$.

[18]. O.Pinho , IMPLVO Ferreira, E.Mendes ,BM. Oliveira and M.Ferreira, Effect of temperature on evolution of free amino acid and biogenic amine contents during storage of Azeitão cheese. Food Chem.,75(3), 2001, 287-291.

[19]. MZ.Zaman, AS.Abdulamir, F.Abu Bakar, J.Selamat and J.Bakar, 2009. A review: microbiological,physiological and health impact of high level of biogenic amines in fish sauce. Am. J. Appl. Sci.6(6),2009, 1199-1211.

[20]. C.Ruiz-Capillas and F. Jiménez Colmenero, Biogenic amines in seafood products. Handbook of seafood and seafood products analysis. Nollet L and Todrà F, (eds). Taylor and Francis Group, LLC,2010.

[21]. A.Halász and A.Baráth , Toxicity of biogenic amines - the present knowledge. In Food Science and technology COST 917 Biogenically active amines in food, Vol VI, EC Publication, Luxembourg,2002.

[22]. S.Brillantes, S.Paknoi , A.Totakien, Histamine formation in fish sauce production.J Food Sci ,67,2002,2090-2094.

[23]. Codex Standard 302-2011 - http://www.codexalimentarius.net/download/standards/11796/CXS 302e.pdf

[24]. A.Ibe, S.Tabata , Y.Sadamasu, A.Yasui , T.Shimoi , M.Endoh and K.Saito , Production of tyramine in "moromi" mash during soy sauce fermentation. Shokuhin Eiseigaku Zasshi. 44(5): 2003, 220-226.

[25]. K.Todoroki , Y.Ishii , C.Miyauchi ,S. Kitagawa, JZ.Min , K.Inoue , T.Yamanaka ,K. Suzuki ,Y. Yoshikawa ,N. Ohashi and T.Toyo'oka. Simple and Sensitive Analysis of Histamine and Tyramine in Japanese Soy Sauces and Their Intermediates Using the Stable Isotope Dilution HILIC-MS/MS Method. J. Agric. Food Chem., 62 (26), 2014, 6206-6211.

[26]. AOAC. 1995a. Histamine in seafood: Biological method. Sec. 35.1.30, Method 954.04. In Official Methods of Analysis of AOAC International, 16th ed., P.A. Cunniff (Ed.), AOAC International, Gaithersburg, MD.,1995.

[27]. L.Beneduce, A.Romano ,V. Capozzi , P.Lucas, L.Barnavon, B.Bach , P.Vuchot P, F.Grieco and G. Spano, Biogenic amins in regional wines. Ann. Microbiol,60,2010, 573-578 
[28]. S.Bover-Cid, M.Izquierdo-Pulido, and MC.Vidal-Carou, Effectiveness of a Lactobacillus sakeistarter culture in the reduction of biogenic amine accumulation as a function of the raw material quality. J. Food Protect.,64(3),2001, 367-373.

[29]. JE.Stratton, RW.Hutkin and SL.Taylor, Biogenic amines in cheese and other fermented foods: a review. J. Food Prot.54,1991, 460-470.

[30]. P.Dalgaard, J.Emborg, A.Kjolby ,N. Sorensen and N.Ballin, Histamine and biogenic amines formation and importance in seafood. In: Improving seafood products for the consumer.BorrensenT, ed. Woodhead Publishing Ltd., Cambridge, UK,2008..

[31]. Codex Alimentarius Commission. 1999. Recommended methods of analysis and sampling(CodexStan 234-1999)

[32]. M.K.Kim , J.H.Mah and Hj.Hwang, Biogenic amine formation and bacterial contribution in fish,squid and shellfish. Food Chem.116,2009, 87-95. 